\title{
An Integrated Monitoring Programme for Doñana Natural Space: The Set-Up and Implementation
}

\author{
Ricardo Díaz-Delgado
}

\section{Donana Natural Space - A Brief Overview}

Protected since 1968, Doñana National Park (537 $\mathrm{km}^{2}$ ) is a UNESCO Biosphere Reserve, a Ramsar Site, a Natural World Heritage Site and is integrated in the Natura 2000 network. It contains the largest wetland in Western Europe (García Novo and Marín Cabrera 2005), an intricate matrix of marshlands $\left(270 \mathrm{~km}^{2}\right)$, phreatic lagoons, and a $25 \mathrm{~km}$-long dune ecosystem with its respective shoreline and representative Mediterranean terrestrial plant communities (Fig. 28.1). The conservation objectives include the preservation of (a) critically endangered species (Iberian lynx Lynx pardina, Spanish imperial eagle Aquila adalberti, marbled teal Marmaronetta angustirostris), (b) the abundance of waterfowl, and (c) the Mediterranean wetlands and terrestrial ecosystems. Furthermore, Doñana is both a critical stopover site for Palearctic birds migrating to Africa and an important overwintering site for waterfowl.

Doñana marshlands have a typical Mediterranean climate: the hydrological cycle starts in September and usually reaches maximum inundation levels during February, mainly driven by the rainfall regime. In late spring, evaporation becomes the most important factor in the water balance, and the marshes dry up slowly until they are completely dry by the end of July. At this time, the aquifer plays a central role in maintaining water levels and permanent lagoons (Grimalt et al. 1999). As is the case for most continental wetlands, interannual variability is driven by meteorological patterns.

\footnotetext{
R. Díaz-Delgado (*)

Head of Landscape \& Remote Sensing Monitoring, Doñana Biological Station-CSIC, c/Américo Vespucio s/n. Isla de la Cartuja, Sevilla, 41092, Spain e-mail: rdiaz@ebd.csic.es
} 


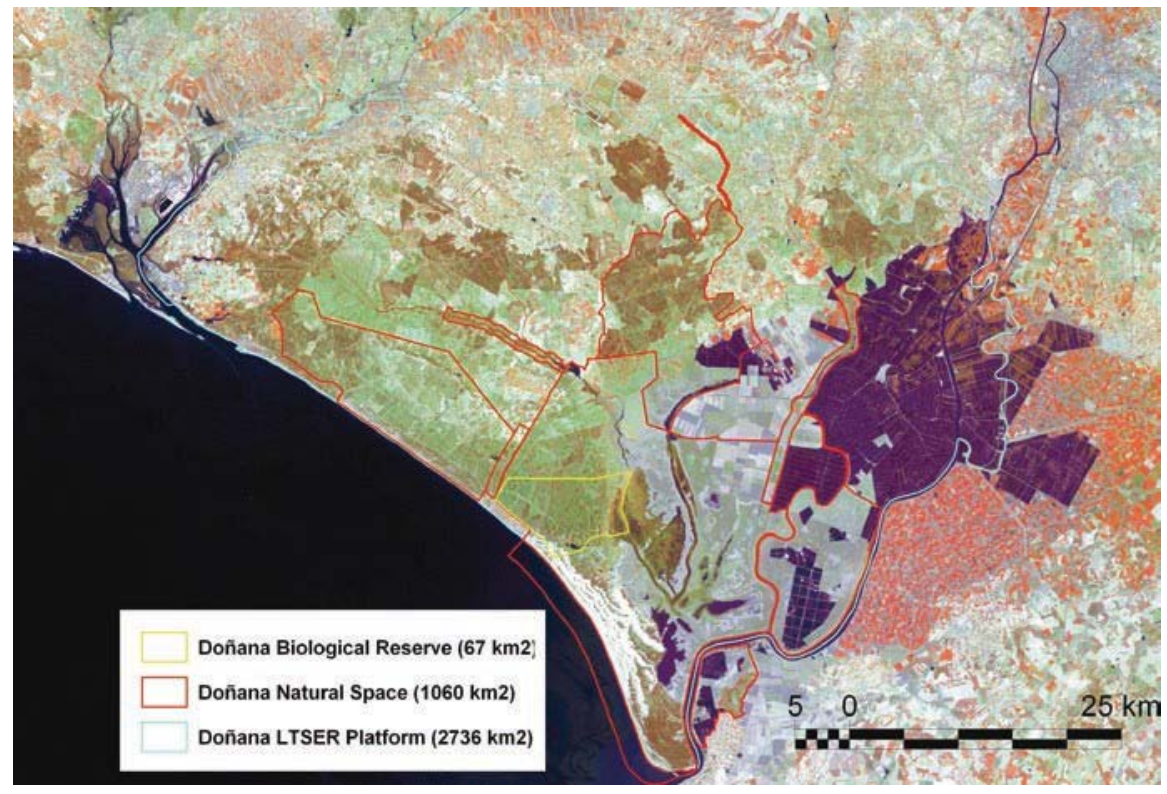

Fig. 28.1 Limits of Doñana Natural Space, Doñana LTSER platform and Doñana Biological Reserve

\section{Historical Monitoring Initiatives and Gaps in Knowledge}

The protection of Doñana was originally promoted by José Antonio Valverde (Fig. 28.2), who faced many challenges and threats before the administration finally declared Doñana a National Park (DNP) in 1969, making it the largest protected area in Spain. Just 6 years previously, J.A. Valverde had already preserved Doñana Biological Reserve (DBR), a 6794 ha plot inside the current National Park (see Fig. 28.1), with the essential help of the World Wildlife Fund. At the same time, he created the Doñana Biological Station (DBS), a specific research centre belonging to the Spanish Research Council (CSIC). Thus, since the very beginning, Valverde, as the first DNP manager and DBS director, firmly linked conservation to research.

Initially, DBS scientific research focused on conservation biology, and especially on threatened species and management benefits. In subsequent years, DBS became a leading research centre on biological conservation topics. From the outset, Valverde passionately promoted the systematic collection of data on relevant conservation variables, such as Iberian lynx population size and distribution, bird banding and band readings or cork oak inventory and marking (Solís 1996). As a consequence, local staff working at DBR began to focus systematically on understanding the most relevant species present in DNP, with staff and visitors keeping field diaries to record both occasional events and daily field work either inside 
Doñana or even overseas (Valverde led many exploratory campaigns in different continents). Also, during that period, monthly aerial waterfowl censuses were introduced to record habitat selection and migratory trends of the most abundant aquatic birds in Doñana marshlands. These, in fact, were the first attempts to establish periodical monitoring activities as the basis for research and management of Doñana's fauna and flora.

In the period from 1970 to 1990, many management decisions for DNP were based on information from field diaries, aerial census reports and assessments. Systematically collected data derived from these research activities have since contributed to publications in international scientific journals (Almaraz and Amat 2004a, b; Rendon et al. 2008).

Despite the obvious interest in, and effort invested in collecting, long-term datasets, these mostly focused on the abundance and occurrence of birds.

It was only in the 1980s that Doñana National Park began focusing more on ecological, limnological, hydrological or ethological issues (García Novo and Marín Cabrera 2005). After the eminent Spanish ecologist Ramón Margalef had described the planktonic community of Doñana lagoons (Margalef 1976), other taxa and natural processes came to be accepted as relevant conservation issues for Doñana.

However, even at the end of the last century, there were still gaps in our knowledge, both from a research and monitoring perspective, particularly relating to topics such as plant physiology, ecophysiology, plant ecology, landscape ecology, land



Fig. 28.2 José Antonio Valverde, the first director of DBS and first manager of DNP 
use cover changes, soil sciences, plant-soil interactions and land cover energy balance. Many of these have since been addressed through the development of an integrated monitoring programme and associated research projects.

\section{The Framework for an Integrated Monitoring Programme: Policy and Opportunity}

Vaughan et al. (2001) defined integrated monitoring as monitoring that uses detailed sets of ecological information, unlike simple monitoring, survey monitoring and proxy monitoring. Although many of the periodical surveys carried out at Doñana acquired relevant data on population condition and breeding success, by the end of the 1990s, the need for an integrated program of long-term ecological monitoring was evident. Therefore, in 2001, a meeting held among DBS and DNP heads led to the proposal for a joint project to set up the integrated ecological longterm monitoring of DNP. Representatives from both institutions (CSIC-DBS and Spanish National Parks Network) agreed on the main features to be monitored according to conservation priorities. The main goal was to achieve long-term knowledge on the dynamics of Doñana natural processes and the conservation management effects on its biodiversity. The conceptual approach focused on monitoring the following features: species, habitats and ecological processes. The species level monitoring focused on the endangered and threatened species, while the foci habitats were mostly the representative and under-represented ones. Finally, the ecological processes did not only include the natural processes interlinking ecosystem functioning and structure but also the human driven impacts (resulting from management decisions - including the conservation measures). Thus, the joint project, entitled "Design and refinement of the integrated programme for monitoring natural processes and resources in Doñana National Park", was initiated in 2002 and devoted 3 years of research to the validation of monitoring protocols and the conceptual model of long-term ecological monitoring. The specific goals of the project were:

1. To achieve an exhaustive bibliographical review of available, up-to-date and standard protocols for the selected features to be monitored.

2. To designate scientific supervisors with recognised expertise in the ecological monitoring targets.

3. To propose feasible monitoring protocols and test their validity and adequacy for monitoring the proposed targets.

4. Final adoption/rejection of the tested methodological protocols and the features proposed for monitoring.

Originally, both institutions agreed on a number of proposed features for monitoring (Tables 28.1 and 28.2). The conceptual approach led to addressing the features under three main monitoring themes and 11 monitoring targets. In addition to flora, fauna, management and geophysical monitoring, a landscape scale monitoring 
Table 28.1 The Biological Monitoring theme, identified targets and features of Doñana Integrated Long Term Ecological Monitoring Programme. Asterisks indicate the features approached at landscape scale

\begin{tabular}{|c|c|c|c|}
\hline Monitoring theme & Target & Feature & Feature description \\
\hline \multirow{29}{*}{ Biological Monitoring } & \multirow{6}{*}{ Vegetation } & NPP & Grass biomass \\
\hline & & Plant cover \& structure & $\begin{array}{l}\text { Pine, cork oak \& juniper woodlands, shrubland, marshland \& riparian } \\
\text { vegetation }(*)\end{array}$ \\
\hline & & \multirow[t]{4}{*}{ Flora } & Aquatic plants distribution and richness \\
\hline & & & Rare threatened plant ssp. distribution and abundance \\
\hline & & & Singular trees inventory \\
\hline & & & Alien spp. distribution and abundance $(*)$ \\
\hline & \multirow[t]{23}{*}{ Fauna } & \multirow[t]{4}{*}{ Terrestrial invertebrates } & Coprophagian Coleoptera abundance \\
\hline & & & Argentine ant abundance and distribution \\
\hline & & & Diurnal butterflies \\
\hline & & & Demographic insect blooms \\
\hline & & \multirow[t]{2}{*}{ Aquatic invertebrates } & Aquatic invertebrates abundance and richness \\
\hline & & & Red crayfish abundance and distribution \\
\hline & & Fish & Fish spp. communities \& abundance \\
\hline & & Amphibians & Amphibians spp. communities \& abundance \\
\hline & & \multirow[t]{5}{*}{ Reptiles } & Greek tortoise distribution \\
\hline & & & Greek tortoise population structure \\
\hline & & & Native turtle distribution \\
\hline & & & Exotic turtle distribution \\
\hline & & & Lizard spp. distribution \& abundance \\
\hline & & \multirow[t]{4}{*}{ Birds } & Vulnerable and endangered birds \\
\hline & & & Passerine communities \\
\hline & & & Bird breeding \\
\hline & & & Wintering birds \\
\hline & & Birds key spp. & $\begin{array}{l}\text { Red-legged partridge and Eurasian coot } \\
\text { abundance and distribution }\end{array}$ \\
\hline & & Mammals key spp. & Rabbit and hare abundance \\
\hline & & \multirow[t]{4}{*}{ Mammals } & Wild ungulates abundance (red deer and wild boar) \\
\hline & & & Water vole abundance \& distribution \\
\hline & & & Carnivore relative abundance \\
\hline & & & Otter abundance and distribution \\
\hline
\end{tabular}


Table 28.2 The Geophysical and Management Monitoring themes, identified targets and features of Doñana Integrated Long Term Ecological Monitoring Programme. Asterisks indicate the features approached at landscape scale

\begin{tabular}{|c|c|c|c|}
\hline Monitoring theme & Target & Feature & Feature description \\
\hline \multirow[t]{7}{*}{ Geophysical Monitoring } & Climate & Meteorology & Meteorological stations \\
\hline & Atmosphere & Air Quality & Pollutant \& Aerosol concentration \\
\hline & Surface water & Flooding dynamics & Marshland flooding dynamics (*) \\
\hline & & & Temporary pools \\
\hline & & Water quality & Water quality \\
\hline & Underground water & Water table & Water table measurements \\
\hline & Geomorphology & Erosion/Sedimentation & $\begin{array}{l}\text { Sedimentation on marshland/Dunar system dynamics/ } \\
\text { Shoreline dynamics }(*)\end{array}$ \\
\hline \multirow[t]{19}{*}{ Management Monitoring } & Hydrology & Water management & Water management evaluation \\
\hline & & & Managed artificial pools \\
\hline & & & Doñana 2005 marshland restoration programme \\
\hline & Vegetation management & Management effects & Plant mowing effects \\
\hline & & & Shrubland clearing effects \\
\hline & & & Silvicultural activities \\
\hline & & & Reforestation with autochtonous plant spp. \\
\hline & & & Alien spp. eradication \\
\hline & Fauna management & & Fauna response to silvicultural activities \\
\hline & & & Iberian lynx population: breeding and mortality \\
\hline & & & Imperial eagle population: breeding and mortality \\
\hline & Land uses and services & & Cattle management \\
\hline & & & Pinenuts harvest management \\
\hline & & & Pilgrimage activities and effects \\
\hline & & & Traffic and public access \\
\hline & & & Beekeeping management \\
\hline & & & Wedge shell fishing activities \\
\hline & & & Land use change around Doñana Natural Space $(*)$ \\
\hline & & & Hunt management \\
\hline
\end{tabular}


approach was proposed to monitor broad-scale processes in the DNP and in its surroundings (unprotected area, see Fig. 28.1). The rationale behind this relies on the need for understanding underlying ecological processes such as connectivity, fragmentation or habitat loss at the landscape scale.

Thus, the main purpose of the programme was to assess individual features using a set of proposed indicators, usually relevant informative variables such as relative and absolute abundance, species distribution, species richness and life condition.

\section{Programme Implementation: Protocol Validation and Arising Issues}

A thorough bibliographical review revealed a complete set of available methods for Doñana features (at least suitable after minor modifications). Most reference sources were supplied by the UK Environmental Change Network (http://www.ecn. ac.uk/), US National Park Service (http://www.nps.gov/), Environment Canada (http://www.ec.gc.ca/) and the Europarc handbook (Atauri et al. 2005), reference guidelines and books as well as scientific papers. During the period 2002-2005, the guidelines of the joint project were to test the validity of the programme. Every feature was then assigned to at least one methodological protocol consisting of:

- The rationale behind the need for feature monitoring (narrative)

- Specific objectives

- State indicators

- Location of sampling sites on the study area, minimum sampling unit and minimum required sampling frequency

- Material and staff needed (Standard Operation Procedures according to Oakley et al. 2003)

Validation mainly consisted of evaluating (through the preliminary monitoring results from the first phase (2002-2005) of the indicators' suitability) the protocols' feasibility and statistical reliability and the actual relevance of proposed features to be monitored.

During this period it became evident which features had been improperly approached, either by using an unsuitable spatial scale, by using unfeasible sampling frequencies or by using inappropriate sampling methods. Often, accessibility was the critical factor to overcome in order to ensure continuous monitoring: for example, to reach the most remote areas inside DNP, trail and track networks often cross deep sand banks, mud covered areas and deep water pools, implying long and harsh journeys to reach monitoring plots and the waste of a full day of labour.

The monitoring protocol for juniper (Juniperus phoenicea ssp. turbinata) woodlands provides an example of how we carried out the validation. The original proposal for this habitat, which is characteristic of top-stabilized coastal sand dunes, was to carry out monitoring every 5 years. However, data gathered during 
the first 3 years stressed the need for a higher sampling frequency to properly record the disturbance effects on the demographic dynamics of this xeric plant community. Many other features were also subjected to a change of sampling frequency and sample size. Other features originally planned as landscape scale projects, such as monitoring of erosion of the Guadalquivir river bank, had to be reassessed due to the inability of automatic remote sensing or digital aerial photograph analysis to easily delineate changes on the river shoreline. Finally, certain standard protocols, in particular those using trapping nets, had to be refined according to the behavioural traits of specific species, e.g. for monitoring the population and abundance of aquatic macroinvertebrates.

After the validation exercise, a further set of monitoring activities were proposed for features not originally considered, such as monitoring phenology, or plant physiology: this is an ongoing process. However, among the leading monitoring institutions there is an implicit awareness of constraining the relevant features to be monitored, based mainly on available funding and resources. From the outset, the responsibility for implementing the long-term ecological monitoring programme in Doñana was assigned to five managers - one for each work area, i.e. landscape scale (which included vegetation dynamics and geomorphological monitoring), amphibians and reptiles, limnology, birds and mammals. In developing the programme, each of these managers had to employ 12 staff members, most of whom were assigned for birds monitoring. During this process, we ran specific training courses for the Doñana monitoring team (ESPN) to facilitate participation, motivation and increase basic monitoring skills. One of the first courses introduced the practical use of GPS and Personal Digital Assistant (PDA) devices. Other courses addressed the identification of Doñana's flora (both aquatic and terrestrial), driving in harsh conditions and health \& safety criteria. Two recent courses have provided the monitoring staff with an introduction to data representation standards (map visualisation of sampling units and variables) and on simple guidelines for reporting results (charts, graphs and tables). A short introduction was also provided on the use of Cybertracker software for data collection through PDAs in the field (see below).

Nowadays, the monitoring programme relies on 15 staff members, ten of whom occupy permanent positions funded by CSIC (Fig. 28.3). However, the programme aims to increase the number of permanent positions in order to achieve the long term monitoring objectives. DBR also runs a volunteer programme that often benefits the monitoring team. Skilled volunteers are periodically recruited to help staff members in baseline monitoring activities, though always after training and under strict staff supervision. This help is gratefully received.

Critically, after a favourable hearing from the Spanish Constitutional Court in 2005, full environmental competences were transferred from the central administration to autonomic governments and, in 2008, the responsibility for DNP management was transferred to the Andalusian regional government. Under this new regime, Doñana Natural Park, (a protected area of 55,300 ha managed by the Andalusian administration that forms a buffer around DNP) was merged for monitoring purposes with DNP. This new and expanded protected area, named Doñana Natural Space (DNS), is now the target area for the monitoring programme, with 


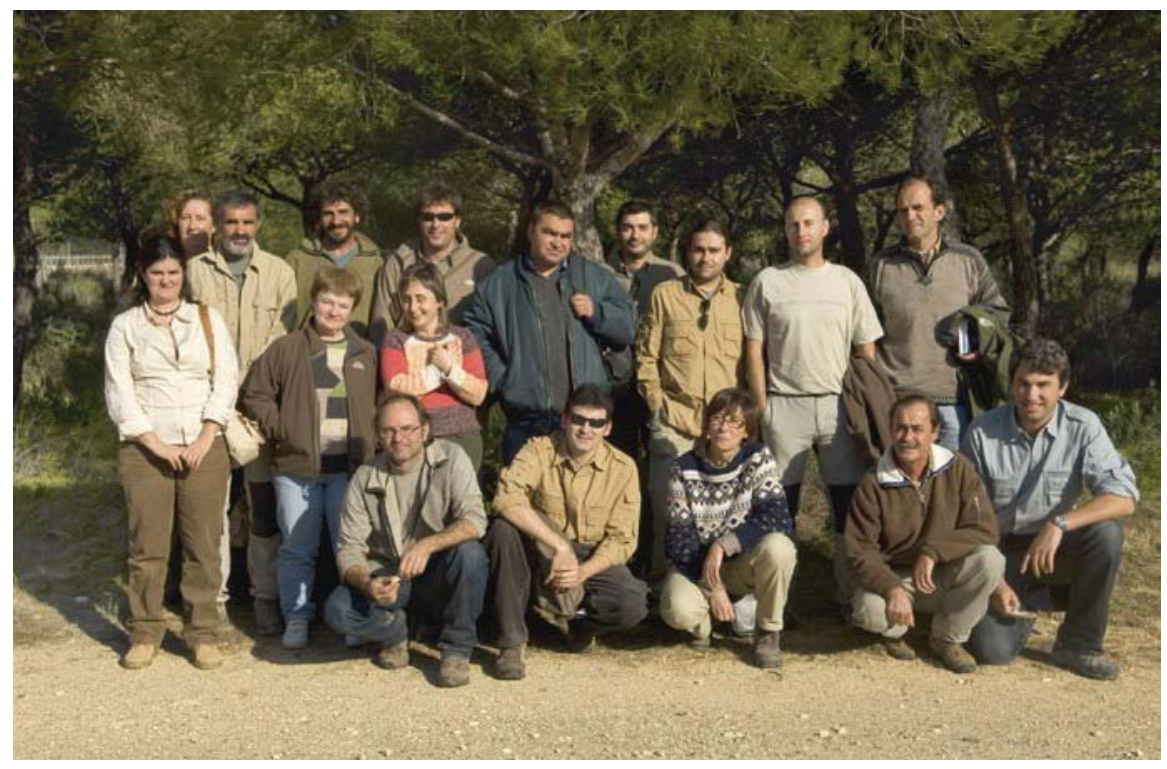

Fig. 28.3 Group picture of most of the staff members devoted to Doñana Integrated Long-Term Ecological Monitoring Programme

major implications for most of the monitoring activities. As a consequence, we have had to enlarge sampling areas, and reduce both the sampling effort and the number of sampling locations inside DNP to achieve the integration. Today, this remains the most pressing challenge for the implementation phase of the DNS monitoring programme.

\section{Automatic Monitoring and Data-Quality Assessment: Enhancing the Programme}

As a consequence of the issues outlined above, we identified the need for automatic procedures to make the monitoring programme cost-effective. Concerns about data quality assessment and metadata management were already evident. Both issues were addressed by different opportune solutions.

The first issue was resolved by Cybertracker: free software (http://www.cybertracker.org/) that uses PDA devices to digitally record any type of observation in the field. It was originally conceived as a tool to improve environmental monitoring by increasing the efficiency of data collection and observer reliability (see Chapter 32 for more information). Since the Doñana monitoring programme began using it there have been two major efficiencies achieved by the combined use of PDAs and 
Cybertracker software: firstly by avoiding the loss of required data, i.e. occasionally required records were just skipped or ignored on site; and secondly by reducing the time needed to digitally archive data by rapid synchronization to the database. However, efficient sequential procedures have to be designed prior to on-site application, and this requires advanced skills in Cybertracker database management.

The second issue was resolved by the recognition of DBR as a Scientific and Technological Singular Infrastructure (ICTS) by the Spanish Ministry of Science and Innovation. Under the Spanish Research Framework Programme, projects of this type qualify for the award of an initial budget to enhance services from such infrastructures to the scientific and technological communities. DBR started to improve the infrastructure by setting up a wireless communication network inside DBR, this was essential and allowed us to install a real-time network of probes, sensors and devices to cover the gaps that we had identified in the monitoring programme. Up to $1 \mathrm{M} €$ was allocated to monitor new features such as soil, below-ground water content and temperature, water quality monitoring, tropospheric $\mathrm{O}_{3}, \mathrm{CO}_{2}$ or enhancing sensor networks such as the meteorological network. ICTS is also providing support for integrating the wireless network with other sensors working in Doñana, sensors that were established a long time ago like the piezometer gauges or hydrological stations. Besides the integrative role played by ICTS for long term ecological monitoring in Doñana, the implementation programme also provides an opportunity for European scientists to apply for short-term prospective projects to be carried out in DNS. Such projects may be proposed under a specific call for projects open twice per year, covering travelling expenses and accommodation. Many of the current ongoing research projects are tightly linked to features already being monitored by enhancing scientific research on global change effects on the Doñana biota.

Interestingly, these solutions have combined to advantage the whole programme, notably through the development of a wireless protocol to easily transfer data gathered in the field (by means of PDA devices) to the central database at the moment of data collection (see Chapter 32). We expect innovative synergies like these to increase the cost-effectiveness of the monitoring programme.

\section{Data Access and Publishing}

Since the outset, one of the premises of the monitoring programme was to make the resulting data publicly available. The only restrictions would apply for conservation purposes, such as locating nesting sites of endangered birds for instance. This mandatory premise has been accomplished by producing reports in which results are presented in tables that are updated annually. Moreover, these reports provide concise interpretations according to the latest observed trends. DNP managers are therefore provided with an annual update on every feature being monitored. However, it is also essential to allow data access through a web page, and over the first 5 years, the ESPN developed a web portal for accessing data results, protocol documentation, annual reports and many other relevant documents at: http://www-rbd. ebd.csic.es/Seguimiento/seguimiento.htm. 
This web page, which is still online at the time of writing, is being transferred progressively to the new ICTS website (http://icts.ebd.csic.es) where results and protocols from manually monitored features are merged in the same database with the results from the automatic procedures. The final web portal will soon allow any visitor to query the central database on results from both approaches (automatic and manual) providing quick insights on trends and the relationship between different indicators.

\section{Success Stories on Data Use for Research and Management}

The main overarching goal of the monitoring programme is to provide baseline information on long-term trends and changes of the monitored features. Accordingly, historical data might be used to set up robust criteria for effective conservation management.

Since 2005, the Doñana management board has considered monitoring results as valid criteria for informing management decisions. The use of baseline trends of ecological indicators in the decision-making process is considered a practical realisation of the monitoring programme's usefulness and success. Early warning monitoring for toxic algal blooms is one such success story. Fully implemented in 2006, the protocol activates a set of management decisions when the indicators reach a standard threshold. Outbreaks of toxic cyanobacteria blooms have occurred periodically in Doñana marshlands causing the poisoning and death of hundreds of different species. During the last 2 years, episodic events have been successfully managed, reducing dramatically the number of affected birds.

On the other hand, monitoring a cork oak (Quercus suber) population (named "La Pajarera”) that is more than 200 years old, where up to 14,000 pairs of herons and storks nest every year causing tree decay, has provided evidence of the need for preventing the depletion of the acorn and seedlings bank by wild herbivores. With a mortality rate of 1.96 individuals per year in the last 43 years, the "Pajarera" site has only recruited 72 individuals by planting and none through natural regeneration. Intensive acorn predation occurs during fruiting season by fallow deer (Dama dama), wild boar (Sus scrofa) and red deer (Cervus elaphus). In 2005, an expert panel proposed a long term restoration programme for this site consisting of several actions, including an experimental design of exclosure fences for testing grazing effects and granting tree recruitment.

\section{Donana LTSER Platform in the ILTER and LTER Europe Networks}

In 2006, DBS joined the European Network of Excellence named ALTERNet (A Long-Term Biodiversity, Ecosystem and Awareness Research Network). ALTER Net aims to establish a lasting infrastructure for integrated ecosystem research. 
This combines ecological and socio-economic approaches, with emphasis on communication with the relevant audiences focusing on the CBD (Convention on Biological Diversity) target of attaining a significant reduction of the current rate of biodiversity loss by 2010. Many of the partner research institutions also participated in the ILTER network (International Long-Term Ecological Research Network) and its regional section of LTER-Europe. During the project development, the LTER-Europe constitution in 2007 proposed the first nine LTSER (Long-Term Socio-Ecological Research) pilot platforms based on selected criteria. The Doñana LTSER platform emerged from this process as a relevant place to investigate socio-economic drivers and pressures on biodiversity following the DPSIR framework (Bugmann and Solomon 2000; Parr et al. 2003; Gobin et al. 2004; Nikolaou et al. 2004). The Doñana LTSER platform includes DNS and the immediate surrounding area, conforming to Doñana County (see Fig. 28.1), in order to assess the effects of human drivers and pressures on biodiversity. The Doñana LTSER platform has started to contribute by developing the socio-ecological long-term research and implementing the DPSIR framework (Haberl et al. 2006). Doñana, together with two other LTSER platforms (Pleine-Fougères in Brittany and Islands of Breila in Romania) have recently reported on an early assessment of EU regulations (Common Agricultural Policy) of unexpected effects on local biodiversity (unpublished ALTERNet Report). The Doñana LTSER platform has also successfully collaborated in the proposal of a conceptual socioecological model for LTSER platforms (Haberl et al. 2009) that will soon be implemented and tested. Both experiences are helping in spreading the LTSER concepts. Since then, DBS has played a major role in setting up the LTER process in Spain. Thus, LTER-Spain was formally accepted as an ILTER and LTEREurope member in 22nd August 2008. It currently comprises 10 sites, including the Doñana LTSER platform. These sites represent the main ecosystems present in the Iberian Peninsula. LTER-Spain has agreed on the minimum common ecological parameters to be monitored by every LTER-site of the network. These parameters cover abiotic variables, primary producers, consumers and other relevant parameters. To date, meteorological variables are the most widely monitored at every LTER-Spain site, closely followed by forestry parameters, birds, invertebrates, soil characteristics, atmospheric deposition, phenology and water body characteristics.

Acknowledgements The author and the ESPN (DNS Monitoring Team) want to sincerely thank the Spanish National Parks Network and CSIC (Spanish Research Council) for the funding by which the joint monitoring project was originally initiated. Also, we want to express our gratitude for the ongoing support from Consejería de Medio Ambiente of Junta de Andalucía (Autonomous Andalusian Government) who are fully committed to the long term monitoring activities in Doñana. Crucial funding support was also provided by the Confederación Hidrográfica del Guadalquivir, the Guadalquivir Catchment Management Institution, through the "Doñana 2005" restoration project. The Ministry of Science and Innovation is also contributing to the long-term support of DBR-ICTS under the Ingenio 2010 initiative. We are also grateful to DNP management administration for its permanent assistance on field work and data sharing. And finally, the ESPN team wants to give special thanks to all the volunteers for their selfless aid in the daily monitoring tasks, sometimes under harsh conditions. The author wants also to thank Clive Hurford for reviewing the manuscript and for his suggestions for improving the readability of the chapter. 


\section{References}

Almaraz P, Amat JA (2004a) Complex structural effects of two hemispheric climatic oscillators on the regional spatio-temporal expansion of a threatened bird. Ecol Lett 7:547-556

Almaraz P, Amat JA (2004b) Multi-annual spatial and numeric dynamics of the white-headed duck Oxyura leucocephala in southern Europe: Seasonality, density dependence and climatic variability. J Anim Ecol 73:1013-1023

Atauri JA, Múgica M, de Lucio JV, Castell C (2005) Diseño de planes de seguimiento en espacios naturales protegidos. Serie Manueales Europarc-España $N^{\circ}$ 2. Fundación Fernando González Bernáldez, Barcelona, 175 pp (in Spanish)

Bugmann HKM, Solomon AM (2000) Explaining forest composition and biomass across multiple biogeographical regions. Ecol Appl 10:95-114

García Novo F, Marín Cabrera C (2005) Doñana: Agua y Biosfera. Ministerio de Medio Ambiente, Sevilla, 354 pp (in Spanish)

Gobin A, Jones R, Kirkby M, Campling P, Govers G, Kosmas C, Gentile AR (2004) Indicators for pan-European assessment and monitoring of soil erosion by water. Environ Sci Policy 7:25-38

Grimalt JO, Ferrer M, Macpherson E (1999) The mine tailing accident in Aznalcollar. Sci Total Environ 242:3-11

Haberl H, Winiwarter V, Andersson K, Ayres RU, Boone C, Castillo A, Cunfer G, FischerKowalski M, Freudenburg WR, Furman E, Kaufmann R, Krausmann F, Langthaler E, LotzeCampen H, Mirtl M, Redman CL, Reenberg A, Wardell A, Warr B, Zechmeister H (2006) From LTER to LTSER: Conceptualizing the socioeconomic dimension of long-term socioecological research. Ecol Soc 11:art. 13

Haberl, H., Gaube, V. Díaz-Delgado, R., Krauze, K. Neuner, A., Peterseil, J., Singh, S.J. and Vadineanu, A. 2009. Towards an integrated model of socioeconomic biodiversity drivers, pressures and impacts. A feasibility study based on three European long-term socio-ecological research platforms. Ecological Economics 68:1797-1812

Margalef R (1976) Algas de agua dulce de Doñana. Oecol Aquat 2:79-91 (in Spanish)

Nikolaou K, Basbas S, Taxiltaris C (2004) Assessment of air pollution indicators in an urban area using the DPSIR model. Fresen Environ Bull 13:820-830

Oakley KL, Thomas LP, Fancy SG (2003) Guidelines for long-term monitoring protocols. Wildlife Soc Bull 31(4):1000-1003

Parr TW, Sier ARJ, Battarbee RW, Mackay A, Burgess J (2003) Detecting environmental change: science and society - Perspectives on long-term research and monitoring in the 21st century. Sci Total Environ 310:1-8

Rendon MA, Green AJ, Aquilera E, Almaraz P (2008) Status, distribution and long-term changes in the waterbird community wintering in Donana, south-west Spain. Biol Conserv 141:1371-1388

Solís JC (1996) Plan de ordenación del alcornocal de Doñana. Doñana Biological Station, unpublished report, 80 pp (in Spanish)

Vaughan H, Brydges T, Fenech A, Lumb A (2001) Monitoring long-term ecological changes through the Ecological Monitoring and Assessment Network: Science-based and policy relevant. Environ Monitor Assess 67:3-28 